\title{
Avaliação da reatividade cruzada entre antígenos de Leishmania spp e Trypanosoma cruzi na resposta sorológica de cães pela técnica de imunofluorescência indireta (RIFI)
}

Raquel Martins LUCIANO' Simone Baldini LUCHEIS ${ }^{1}$ Marcella Zampoli TRONCARELLI ${ }^{1}$

Daniela Martins LUCIANO'1 Hélio LANGONI ${ }^{1}$

\section{Correspondência para:}

Simone Baldini Lucheis, Rodovia Mal Rondon, Km279, Caixa Postal 108 São Manuel-SP, CEP 18650-970, silucheis@apta.sp.gov.br

Recebido para publicação: 22/11/2007 Aprovado para publicação: 28/08/2008

\author{
1 - Faculdade de Medicina Veterinária e Zootecnia da Universidade Estadual \\ Paulista, Botucatu-SP
}

\section{Resumo}

A leishmaniose visceral (LV) é uma zoonose causada por protozoários do gênero Leishmania. O cão é o principal reservatório do parasito, especialmente em áreas urbanas. A Reação de Imunofluorescência Indireta (RIFI) é comumente empregada para o diagnóstico da leishmaniose visceral canina (LVC), baseada na detecção de anticorpos contra o parasito. Entretanto, reações cruzadas com Trypanosoma cruzi podem ocorrer à sorologia. Com o objetivo de avaliar as reações cruzadas entre os antígenos de Leishmania spp. e de T.cruzi, foram colhidas 150 amostras de sangue de cães positivos para LVC em inquérito epidemiológico e os soros foram testados pela RIFI. Os cães foram submetidos à eutanásia no Centro de Controle de Zoonoses de Bauru (SP), área endêmica para LV. Outras 150 amostras de sangue de cães foram colhidas em Botucatu (SP), área não endêmica para LV, e os soros foram também testados pela RIFI. Os soros de cães procedentes de Bauru resultaram positivos, tanto para Leishmania spp. quanto para T.cruzi, demonstrando uma grande incidência de reações cruzadas, reforçando a necessidade da confirmação diagnóstica por outras técnicas. As amostras de soros de cães procedentes de Botucatu (SP), pela técnica de RIFI, demonstraram baixa prevalência de resultados positivos para Leishmania spp. e para T.cruqi. Entretanto, apesar do reduzido número de resultados positivos à sorologia para ambos parasitos, a investigação sorológica e epidemiológica para LV e doença de Chagas em cães de Botucatu deve ser mantida, considerando a importância do cão como reservatório doméstico no contexto destas zoonoses.

\section{Introdução}

As leishmanioses referem-se a uma variedade de doenças causadas por protozoários do gênero Leishmania, envolvendo diferentes espécies. São doenças infecciosas, transmitidas por mosquitos flebotomíneos, apresentando curso crônico com sinais cutâneos, muco-cutâneos e sistêmicos. São reconhecidas três formas de apresentação, como a leishmaniose visceral ou calazar, a leishmaniose cutânea e ainda a leishmaniose mucocutânea. ${ }^{1}$

No Brasil, a leishmaniose, bem como

\author{
Palavras-chave: \\ Leishmaniose visceral canina. \\ Doença de Chagas. \\ Reação cruzada. \\ Sorologia. \\ Inquérito epidemiológico.
}

a doença de Chagas, são importantes endemias de caráter zoonótico que podem produzir expressivos distúrbios orgânicos em seres humanos e, por isso, exigem reiterados cuidados sob o ponto de vista médicoassistencial. Causadas pelos protozoários das espécies do gênero Leishmania spp. e Trypanosoma cruzi (T. cruql), respectivamente ${ }^{2}$, ambos têm como vetores insetos hematófagos (Lutzomyia spp. e triatomíneos, respectivamente). Os canídeos silvestres e domésticos são os principais reservatórios destes parasitos.

A Leishmaniose Visceral (LV) é 
caracterizada por uma marcada estimulação policlonal de linfócitos $\mathrm{B}$, que resulta em hipergamaglobulinemia e elevada produção de anticorpos, o que facilita o diagnóstico pelos testes sorológicos, evitando os métodos parasitológicos, que são invasivos. ${ }^{3}$ Os testes sorológicos, principalmente em inquéritos epidemiológicos de busca ativa, são as principais ferramentas para a identificação de cães infectados por Leishmania spp. A Reação de Imunofluorescência Indireta (RIFI), frequentemente utilizada nestes inquéritos, está sujeita à ocorrência de reações cruzadas com antígenos de T.cruæi, especialmente pela proximidade filogenética entre os parasitos. O reconhecimento de reações cruzadas entre diferentes infecções nos diagnósticos sorológicos é clássico, principalmente quando são utilizados antígenos não purificados. ${ }^{4}$.

Após a infecção por Leishmania spp., alguns cães desenvolvem sintomas da enfermidade com um título crescente de anticorpos. Entretanto, podem ocorrer dificuldades no diagnóstico sorológico, associadas à detecção das reações cruzadas com T.cruzi, prejudicando a interpretação dos resultados. Além disso, pode haver uma redução na resposta imune, levando a não significância nos títulos de anticorpos, e o animal não apresentar sintomas. ${ }^{5}$

A RIFI, utilizada a partir da década de 60, indicada pelo Ministério da Saúde para o diagnóstico e levantamento epidemiológico para leishmaniose, apresenta elevadas sensibilidade (90-100\%) e especificidade (80\%). ${ }^{6,7,8,9} \mathrm{Uma}$ das principais limitações da RIFI é a ocorrência de reações cruzadas, principalmente com a doença de Chagas. Os antígenos utilizados nos testes diagnósticos de RIFI e ELISA são geralmente derivados de promastigotas de cultura, parasitos intactos ou moléculas solúveis. Estes antígenos apresentam reações cruzadas com outras espécies da família Trypanosomatidae, e mesmo com microrganismos filogeneticamente distantes. ${ }^{10}$ Portanto, no diagnóstico sorológico da LVC é necessário considerar o diagnóstico diferencial com a doença de
Chagas, atentando-se para os sintomas do animal, se este os apresentar, e também os aspectos epidemiológicos, tais como a procedência do animal (área endêmica ou não para leishmaniose e doença de Chagas), presença de vetores (flebotomíneos, no caso da leishmaniose e triatomíneos, para a doença de Chagas) e o contato do cão com animais silvestres, já que estes também são reservatórios importantes, tanto de Leishmania spp. quanto de T. cruzi. No caso de haver reações cruzadas entre T. cruzi $i$ e Leishmania spp., deve-se levar em consideração o resultado sorológico, associado aos fatores clínicos e epidemiológicos, bem como utilizar de outros instrumentos para o diagnóstico diferencial.

Com base no exposto, o objetivo do presente estudo foi avaliar a ocorrência de reações cruzadas com antígenos de T. cruzi em soros de cães procedentes de área endêmica para LVC, representada pela cidade de Bauru (SP), e em soros de cães procedentes de área considerada até o presente momento não endêmica para LVC, como é o caso de Botucatu (SP). Tendo em vista que os cães são reservatórios importantes, tanto de leishmanias, quanto de tripanossomatídeos, tal estudo possibilitou também analisar a detecção de anticorpos contra Leishmania spp. e T. cruqi, como investigação epidemiológica de ambas zoonoses, consideradas de grande importância em saúde pública.

\section{Material e Método}

A reação cruzada entre antígenos de Leishmania spp. e de T.cruzi foi avaliada em 150 soros de cães encaminhados para eutanásia no Centro de Controle de Zoonoses (CCZ) da cidade de Bauru (SP), e em 150 soros de cães procedentes de Botucatu (SP). Para isso, utilizou-se a técnica RIFI para detecção de anticorpos anti- $T$. cruəi e anti-Leishmania spp.

RIFI para Leishmania spp.

Foram utilizadas lâminas de imunofluorescência impregnadas com os 
antígenos de Leishmania major, confeccionadas no Laboratório de Diagnóstico de Zoonoses, do Departamento de Higiene Veterinária e Saúde Pública, da FMVZ/UNESP - Campus de Botucatu (SP). As amostras foram diluídas a 1:40 em solução salina tamponada, como triagem da reação e, imediatamente testadas para anticorpos anti-IgG para Leishmania major, como descrito pelo método de Camargo ${ }^{11}$. Havendo positividade, o soro foi novamente diluído até a última diluição onde ainda se observava fluorescência. Foram considerados positivos os títulos com fluorescência a partir da diluição 1:40.

\section{RIFI para T.cruzi}

Foram utilizadas lâminas de imunofluorescência impregnadas com os antígenos de T. cruzi (cepa Y), confeccionadas no laboratório de diagnóstico de Zoonoses do Departamento de Higiene Veterinária e Saúde Pública, da FMVZ/UNESP - Campus de Botucatu (SP).

Os soros foram diluídos inicialmente a 1:20 em solução salina tamponada, como triagem da reação, e prontamente testados para anticorpos anti-IgG para T.cruzi, como descrito pelo método de Camargo ${ }^{11}$. Havendo positividade, o soro foi novamente diluído até a última diluição onde se observava fluorescência. Foram considerados positivos os títulos com fluorescência a partir da diluição 1:20.

\section{Resultados e Discussão}

Em muitas localidades da América do Sul, existem áreas endêmicas, tanto para leishmaniose quanto para doença de Chagas. Leishmania spp. e T. cruzi, agentes causais destas parasitoses, respectivamente, pertencem à família Trypanosomatidae e compartilham vários antígenos que causam reação cruzada no diagnóstico sorológico quando misturas de complexos antigênicos são utilizadas. ${ }^{12,13}$

Analisando-se os resultados finais obtidos no presente estudo, observou-se que, em soros de cães procedentes de Bauru (SP), houve positividade sorológica tanto para Leishmania spp. quanto para T. crųi, demonstrando uma grande incidência de reações cruzadas nesses animais, necessitando portanto de confirmação diagnóstica pela detecção específica do DNA do parasito, pela técnica da Reação em Cadeia pela Polimerase (PCR). Das 150 sorologias pareadas para Leishmania spp. e T.cruzi, 94 soros $(62,7 \%)$ demonstraram título para Leishmania spp. maior que para T. cruzi; 16 soros $(10,7 \%)$ revelaram títulos para Leishmania spp. idênticos àqueles contra $T$. cruzi; cinco soros $(3,3 \%)$ demonstraram títulos para Leishmania spp. menores do que para T.cruzi; e 35 soros $(23,3 \%)$ apresentaram títulos para T. cruzi negativos. Pôde-se verificar também que, em quatro soros $(2,7 \%)$, houve uma grande diferença na titulação para Leishmania spp. e para T.cruži, sugerindo intensa reação cruzada (título 5120 e 80 , respectivamente, em um soro e título 2560 e 20 , respectivamente, em três soros. Em 16 soros $(10,7 \%)$ houve resultados de titulação sugestivos de reação cruzada de Leishmania spp. com T. cruzi, já que os títulos para Leishmania spp. eram maiores que os títulos para T. cruzi e, em 42 soros $(28 \%)$ os títulos para Leishmania spp. eram muito próximos aos títulos de T. cruæi, e, portanto, outros métodos diagnósticos deveriam ser utilizados para se chegar ao diagnóstico definitivo. Em 53 soros (35,3\%), os títulos para Leishmania spp. e T. cruzi apresentaram uma diluição de diferença apenas, ou iguais, necessitando a comprovação do diagnóstico também por outras técnicas, como a PCR (Tabela 1).

Nos casos de LV, comumente são detectados títulos elevados de anticorpos no soro pela RIFI, geralmente superiores a 80 , sendo que títulos inferiores necessitam de confirmação por outras metodologias. ${ }^{14} \mathrm{~A}$ média dos títulos sorológicos para leishmaniose dos animais provenientes de Bauru foi de 777,86 (com intervalo de confiança a $90 \%$ de $\pm 130,66)$, sendo a moda o título de 640, restando poucas dúvidas em relação à real positividade destes cães para a enfermidade. Em contrapartida, a média dos títulos sorológicos para doença de Chagas, nestes mesmos animais, foi de 
Tabela 1 - Número de amostras com resposta sorológica para Leishmania spp. e T. cruzi e respectivos títulos obtidos na prova de Reação de Imunofluorescência Indireta (RIFI), em soros de cães provenientes de Bauru (SP) - Botucatu - 2006

\begin{tabular}{|c|c|c|c|c|c|c|c|c|c|c|c|}
\hline \multirow{13}{*}{ 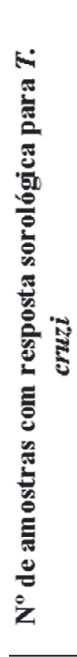 } & \multicolumn{11}{|c|}{ Número de amostras com resposta sorológica para Leishmania spp. } \\
\hline & & NR & 40 & 80 & 160 & 320 & 640 & 1280 & 2560 & 5120 & Totais \\
\hline & NR & - & 4 & 3 & 8 & 9 & 9 & 2 & - & - & 35 \\
\hline & 20 & - & 5 & 1 & 1 & $\mathbf{1}$ & 2 & - & 3 & - & 13 \\
\hline & 40 & - & 3 & 2 & 4 & 5 & 3 & - & - & - & 17 \\
\hline & 80 & - & 2 & 3 & 3 & 5 & 4 & 3 & 2 & 1 & 23 \\
\hline & 160 & - & - & 1 & 4 & 8 & 6 & 6 & 4 & 1 & 30 \\
\hline & 320 & - & - & - & - & 3 & 13 & 3 & 4 & - & 23 \\
\hline & 640 & - & - & - & - & 2 & 2 & - & 3 & - & 7 \\
\hline & 1280 & - & - & - & - & - & - & - & - & 1 & 1 \\
\hline & 2560 & - & - & - & - & - & - & - & 1 & - & 1 \\
\hline & 5120 & - & - & - & - & - & - & - & - & - & 0 \\
\hline & Totais & 0 & 14 & 10 & 20 & 33 & 39 & 14 & 17 & 3 & \\
\hline
\end{tabular}

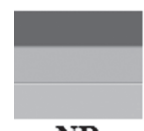

NR

Titulação altamente sugestiva de reação cruzada de Leishmania spp. com $T$. cruzi

Titulação sugestiva de reação cruzada de Leishmania spp. com $T$. cruzi

Titulação pouco sugestiva de reação cruzada de Leishmania spp. com T. cruzi

Não reagente

155,06 (com intervalo de confiança a 90\% de $\pm 35,96)$, sendo a Moda as sorologias com títulos inferiores a 20 , indicando negatividade para T. cruqi. Zanette ${ }^{15}$ verificou a ocorrência de possíveis reações cruzadas entre antígenos de T. cruzi, Ehrlichia canis, Babesia canis, Toxoplasma gondï $\mathrm{e}$ Neospora canimum com Leishmania chagasi, por meio dos métodos de ELISA, RIFI e imunocromatografia. Das 14 amostras de soro positivas para doença de Chagas, nove $(64,3 \%)$ foram consideradas positivas pela técnica de ELISA e seis (42,9\%) pela RIFI, não se observando resultados positivos por imunocromatografia. Das 13 amostras de soro de animais portadores de erliquiose, uma $(7,7 \%)$ apresentou resultado positivo por meio dos métodos de ELISA e de imunocromatografia. Das seis amostras de soro de cães apresentando co-infecção por erliquiose e babesiose, cinco (83,3\%) foram classificadas como positivas pela técnica de ELISA e três $(50,0 \%)$ por imunocromatografia, não se observando resultados positivos pela RIFI. Das 10 amostras de soro de cães com toxoplasmose, cinco $(50 \%)$ foram positivas pela RIFI e uma (10\%) por imunocromatografia, não ocorrendo reação cruzada pela técnica de ELISA. Somente uma $(12,5 \%)$ das oito amostras de soro de cães com neosporose obteve resultado positivo pela técnica de imunocromatografia, e das 13 amostras de soro de cães com coinfecção pela toxoplasmose e neosporose, três $(23 \%)$ foram positivas por meio da técnica de imunocromatografia. Das 12 amostras de soro de cães com babesiose, nenhuma apresentou reação positiva pelos três testes empregados.

A causa das críticas ou insatisfações geradas com o sacrifício de animais, caracterizados como positivos para leishmaniose, pode ser minimizada se for considerado que a menor especificidade da RIFI é devida, em parte, à existência de reações cruzadas com doenças causadas por outros tripanossomatídeos, como a doença de Chagas aqui analisada e a Leishmaniose Tegumentar Americana (LTA), ou seja, os animais falsos positivos para LV, podem ser, por seu turno, positivos para essas enfermidades. Entretanto, da mesma forma que para a LV canina, o sacrifício do cão positivo para doença de Chagas e LTA 
também é recomendado por não existir tratamento eficaz e o animal também constituir um importante reservatório dessas doenças para o ser humano. A questão que se coloca frente à situação de sacrifício de animais falsos positivos é a necessidade de aprimoramento das técnicas diagnósticas, principalmente no que concerne à especificidade do teste utilizado para detecção do reservatório animal, uma vez que essa propriedade interfere no valor preditivo positivo do teste. ${ }^{16}$

Em soros de cães procedentes de Botucatu (SP), a pesquisa mostrou baixa prevalência de positividade para Leishmania spp. e T. cruzi. Das 150 sorologias realizadas, 136 amostras $(90,6 \%)$ foram não reagentes para ambos parasitos; três cães $(2 \%)$ apresentaram títulos para Leishmania spp. maiores que para T. cruzi, com três diluições a mais; um cão $(0,7 \%)$ foi reagente para Leishmania spp. e T. cruzi, com títulos 320 e 160, respectivamente, demonstrando uma possível infecção mista, já que ambos títulos estão muito próximos. Este fato leva a um estado de alerta para a vigilância epidemiológica para ambas enfermidades em Botucatu. Além disso, cinco cães (3,3\%) apresentaram título para T. cruzi, e não foram reagentes para Leishmania spp. Apesar do reduzido número de reagentes para $T$. cruži, a importância da investigação sorológica para este agente em Botucatu deve ser mantida, como demonstrado no trabalho de Lucheis et al. ${ }^{17}$. Dois cães $(1,4 \%)$ apresentaram títulos iguais para ambos parasitos; três cães $(2 \%)$ apresentaram títulos para T. cruzi negativos, e positivos para Leishmania spp., demonstrando ser provavelmente um título de infecção para leishmaniose sem a ocorrência da reatividade cruzada (Tabela 2). Até o presente momento não foram encontrados estudos que evidenciem a presença de flebótomos do gênero Lutzomyia na cidade de Botucatu indicando, no caso dos animais com títulos positivos para Leishmania spp., que estes provavelmente eram procedentes de regiões endêmicas.

Portanto, a identificação de indivíduos falsos positivos pela RIFI se deve às reações cruzadas entre a LVC e duas outras importantes zoonoses: LTA e doença de Chagas. Este fato pode ser inconveniente quando os objetivos são os levantamentos epidemiológicos e o conhecimento da distribuição espacial da LVC, da LTA ou da doença de Chagas nos reservatórios caninos, já que as áreas de concomitância dessas doenças são comuns em nosso país. Por outro lado, as falhas de especificidade das técnicas são minimizadas, pois, as três

Tabela 2 - Número de amostras com resposta sorológica para Leishmania spp. e T .cruzi e respectivos títulos obtidos na prova de Reação de Imunofluorescência Indireta (RIFI), em soros de cães provenientes de Botucatu (SP) - Botucatu - 2006

\begin{tabular}{|c|c|c|c|c|c|c|c|c|c|c|c|}
\hline \multirow{13}{*}{ 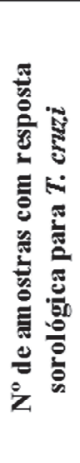 } & \multicolumn{11}{|c|}{ Número de amostras com resposta sorológica para Leishmania spp. } \\
\hline & & NR & 40 & 80 & 160 & 320 & 640 & 1280 & 2560 & $\mathbf{5 1 2 0}$ & Totais \\
\hline & NR & 136 & 1 & & & 1 & 1 & & & & 139 \\
\hline & 20 & 4 & & & 1 & & & & & & 5 \\
\hline & 40 & & 1 & & & 1 & & & & & 2 \\
\hline & 80 & 1 & & 1 & & & & & & & 2 \\
\hline & 160 & & & & & 1 & & 1 & & & 2 \\
\hline & 320 & & & & & & & & & & 0 \\
\hline & 640 & & & & & & & & & & 0 \\
\hline & 1280 & & & & & & & & & & 0 \\
\hline & 2560 & & & & & & & & & & 0 \\
\hline & 5120 & & & & & & & & & & 0 \\
\hline & Totais & 141 & 2 & 1 & 1 & 3 & 1 & 1 & 0 & 0 & \\
\hline
\end{tabular}

Titulação altamente sugestiva de reação cruzada de Leishmania spp. com T.cruzi

Titulação sugestiva de reação cruzada de Leishmania $\operatorname{spp} . \operatorname{com} T$. cruzi

Titulação pouco sugestiva de reação cruzada de Leishmania spp. com $T$. cruzi

NR Não reagente 
zoonoses, endêmicas no Brasil, apresentam a espécie canina como reservatória do parasito e fontes de infecção para o ser humano e outros animais, não havendo tratamento eficiente para tais doenças. Portanto, permanece necessária a medida adotada de eutanásia dos cães para o controle destas enfermidades. ${ }^{16}$

Nas situações onde os soros apresentaram títulos positivos para T. cruqi, superando os títulos para Leishmania spp.; soros com títulos muito altos para T. cruzi $i \mathrm{e}$ Leishmania spp., ou nos casos onde ocorreu apenas positividade para T. cruzi, deve-se considerar a possibilidade de uma real infecção por T. cruzi. Segundo Lucheis et al. ${ }^{17}$, a freqüência de infecções por tripanosomatídeos, comprovada por exames de PCR para T. cruzi e/ou T. rangeli, poderia ser devido à transmissão ativa destes parasitos nos cães pela presença do vetor e, em casos de ausência de triatomíneos, poderia ser considerada a possibilidade de que a infecção parasitária acontecesse por roedores ou outros animais silvestres, frequentemente presentes no peridomicílio e/ou domicílio, devido ao desequilíbrio ecológico.

\section{Conclusões}

Os soros de cães procedentes de Bauru apresentaram positividade sorológica, tanto para Leishmania spp. quanto para
T.cruzi, demonstrando uma elevada incidência de reações cruzadas pela RIFI, necessitando, portanto, da confirmação diagnóstica por outras técnicas, como a PCR; em soros de cães procedentes de Botucatu (SP), pela técnica de RIFI, a ocorrência de anticorpos anti-Leishmania spp. e anti-T.cruzi foi baixa. Entretanto, apesar do reduzido número de resultados positivos à sorologia para ambos parasitos, a investigação sorológica e epidemiológica para LV e doença de Chagas em cães de Botucatu deve ser mantida, considerando a importância do cão como reservatório doméstico no contexto destas zoonoses.

\section{Agradecimentos}

Ao Laboratório de Diagnóstico de Zoonoses e a todos os residentes e pósgraduandos do Departamento de Higiene Veterinária e Saúde Pública da FMVZUNESP, campus de Botucatu-SP; ao Laboratório de Patologia Clínica e a todos os residentes do Departamento de Clínica Veterinária da FMVZ-UNESP, campus de Botucatu-SP; ao Centro de Controle de Zoonoses do município de Bauru-SP e Canil Municipal de Botucatu-SP; a todas as demais pessoas que tornaram possível a realização deste trabalho; a Fundação de Amparo à Pesquisa do Estado de São Paulo - FAPESP Processo $n^{\circ}$ 05/03224-0, pelo suporte financeiro.

\section{Cross reaction evaluation of Leishmania spp and Trypanosoma cruziantigens in dogs' serologic response by indirect immunofluorescence test (IIF)}

\begin{abstract}
Visceral Leishmaniasis (VL) is a zoonosis caused by Leishmania spp. protozoa. Dog is the main parasite's reservoir, especially in urban areas. Indirect Immunofluorescent Antibody Test (IFAT) is commonly used for canine visceral leishmaniasis (CVL) diagnosis, by detection of antibodies against the parasite. However, Trypanosoma cruqi (T.cruri) cross reactions can occur in serological diagnosis. In order to evaluate the occurrence of cross reactions between antigens of Leishmania spp. and T.cruzi, 150 blood samples of CVL epidemiological inquiry positive dogs were collected and sera were tested by IFAT. Dogs were culled at Zoonosis Control Center of
\end{abstract}

Key words:

Canine visceral leishmaniasis. Chagas' disease.

Cross reaction.

Serology.

Epidemiological inquiry. 
Bauru (SP), an endemic area for VL. Another 150 dogs' blood samples were collected in Botucatu (SP), a non endemic area for $\mathrm{LV}$, and sera were also tested by IFAT. Serum samples of dogs from Bauru were positive, both for Leishmania spp. and for T. cruqi, showing high cross-reactions incidence, reinforcing the need of diagnosis confirmation by other tests. Serum samples of dogs from Botucatu demonstrated low prevalence of positive results by IFAT, both for Leishmania spp. and T.cruqi. However, despite the low number of positive serological results for these parasites, the epidemiological and serological investigation for LV and Chagas disease in dogs from Botucatu must be kept, considering the importance of dog as domestic reservoir for both parasites.

\section{Referências}

1 LAINSON, R.; SHAW, J. J. Evolution, classification and geographic distribution. In: PETERS,W.; KILLICKKENDRICK R. The leishmaniases in biology and medicine. London: Academic Press, 1987. v. 1, p. 100120

2 SIMÕES-MATTOS, L.; MATTOS, M. R. F.; TEIXEIRA M. J.; OLIVEIRA-LIMA, J. W.; BEVILAQUA, C. M. L.; PRATA-JÚNIOR, R. C.; HOLANDA, C. M.; RONDON, F. C. M.; BASTOS, K. M. S.; COELHO, Z. C. B.; COELHO, I. C. B.; BARRAL, A.; POMPEU, M. M. L. The susceptibility of domestic cats (Felis catus) to experimental infection with Leishmania braziliensis Veterinary Parasitology, v. 127, n. 3/4, p. 199-208, 2005.

3 HENDRICK, R. The leishmaniasis in biology and medicine. London: Academic Press, 1987. p. 1-20.

4 BRENER, Z.; ANDRADE, Z. A.; BARRAL-NETTO, M. Diagnóstico Laboratorial da Infecção pelo Trypanosoma cruzi In: Brener, Z. e Andrade, Z.A Trypanosoma cruzi e Doença de Chagas. 2. ed. Rio de Janeiro: Guanabara Koogan, 2000. p. 344-378.

5 KILLICK-KENDRICK, R.; KILLICK-KENDRICK, M.; FOCHEUX, C.; DEREURE, J.; PUCCH, M. P. CADIERGUES, M. C. Protection of dogs from bites of phlebotomine sandflies by deltamethrin collars for control of canine leishmaniasis. Medical and Veterinary Entomology, v. 11, n. 2, p. 105-111, 1997.

6 GENARO, O. Leishmaniose visceral. In: NEVES, D.P.; MELO, A.L.; GENARO, O.; LINARDI, P.M. (Org.). Parasitologia humana. Rio de Janeiro: Livraria Atheneu, 2000. p. 56-72

7 HARITH, A. E.; KOLK, A. H. J; LAARMAN, J. J. Evaluation of a newly developed direct agglutination test (DAT) for serodiagnosis and sero-epidemiological studies of visceral leishmaniasis: comparison with IFAT and Elisa. Transactions of the Royal Society of Tropical Medicine and Hygiene, v. 81, n. 4, p. 603-606, 1987.

8 LANGONI, H.; LUCHEIS, S. B.; DA SILVA, R. C. CASTRO, A. P. B.; PAES, A. C. American visceral leishmaniasis: A case report. Journal of Venomous Animals and Toxins including Tropical Diseases, v. 11 n. 3 p. 360-371, 2005.

9 MOHAMMED, A. R; WRIGHT, E. P.; RAHMAN, A. $M$. Serodiagnosis of Sudanese visceral and mucosal leishmaniasis: comparision of Elisa-imunofluorescence and indirect haemagglutination. Transactions of the Royal Society of Tropical Medicine and Hygiene, $v$. 80, n. 2, p. 271-274, 1986.

10 SUNDAR, S.; RAI, M. Laboratory diagnosis of visceral leishmaniasis. Clinical and Diagnostic Laboratory Immunology, v. 9, n. 5, p. 951-958, 2002.

11 CAMARGO M. E.; REBONATO, C. Cross reactivity in fluorescence tests for Trypanosoma and Leishmania antibodies. A simple inhibition procedure to ensure specific results. The American Journal of Tropical Medicine and Hygiene, v. 18, n. 4, p. 500-505, 1966.

12 CHIARAMONTE M. G.; ZWIRNER N. W.; CAROPRESI S. L.; HEREDIA, V. Study of cases of leishmaniasis in the Province of Salta: evidences of mixed infection with Trypanosoma cruzi and Leishmania sppp. Medicina (Buenos Aires), v. 56, n. 3, p. 259-268, 1996.

13 ROSARIO, E. Y. Avaliação de testes sorológicos utilizando antígenos brutos e recombinantes para o diagnóstico da leishmaniose visceral canina. 2002. 99 p. Dissertação (Mestrado em Parasitologia) Universidade Federal de Minas Gerais, Belo Horizonte, 2002.

14 CAMACHO, A. A.; TEIXEIRA, M. S. S.; OLIVEIRA ALVES, R. Eletrocardiography in adult dogs infected with Trypanosoma cruzi during acute and chronic phases. Ars Veterinária, v. 16, n. 3, p. 158-164, 2000.

15 ZANETTE, M. F. Comparação entre os métodos de ELISA, imunofluorescência indireta e imunocromatografia para o diagnóstico da leishmaniose visceral canina. 2006. 92 f. Dissertação (Mestrado em Ciência Animal). Faculdade de Odontologia, Universidade Estadual Paulista Julio de Mesquita Filho, Araçatuba, 2006.

16 ALVES, W. A; BEVILACQUA, P. D. Reflexões sobre a qualidade do diagnóstico da leishmaniose visceral canina em inquéritos epidemiológicos: o caso da epidemia de Belo Horizonte, Minas Gerais, Brasil, 1993-1997. Caderno de Saúde Pública, v. 20, n. 1, p. 259-265, 2004.

17 LUCHEIS, S. B.; DA SILVA, A. V.; ARAÚJO JR. J.P.; LANGONI, H.; MEIRA, D. A.; MARCONDESMACHADO, J. Trypanosomatids in dogs belonging to individuals with chronic Chagas' Disease living in Botucatu town and surrounding region, São Paulo state, Brazil. Journal of Venomous Animals and Toxins including Tropical Diseases., v. 11, n. 4, p. 492-509, 2005. Disponível em: <www.jvat.org.br>. Acesso em: 23 out. 2006 